\title{
De la geopolítica de la dominación a las geo-grafías políticas de la des/colonialidad del poder
}

\author{
From the geopolitics of domination to the geographies of the politics \\ of the des / coloniality of power
}

\author{
Juan Manuel Delgado Estrada
}

\begin{abstract}
Universidad Nacional Mayor de San Marcos. Consejo Latinoamericano de Ciencias Sociales. Unión Geográfica Internacional. juan.delgado10@unmsm.edu.pe
\end{abstract}

\begin{abstract}
RESUMEN
Se desea abrir el debate dentro de la geografía y su relación con las ciencias sociales sobre este hito dimensional de la génesis de la geografía como ciencia social desde Estrabón, su institucionalización en la academia, su génesis como geografía política de origen biologicista darwinista, su posterior mutación como geopolítica y su uso como parte de la política expansionista de los países imperiales del siglo XIX. La geografía y el oficio de geógrafo fueron transformados por la geopolítica como un arma de dominación en el espacio y tiempo de Europa y "Latinoamérica". La geopolítica y la geografía anarquista fueron víctimas de las consecuencias de las hegemonías en el campo académico y militar. La primera fue acusada de conspirar a favor de los nazis en la II Guerra Mundial y la teoría anarquista fue acusada por el marxismo de no ser rigurosa científicamente; ambas fueron desaparecidas o proscritas de la academia hasta hace poco tiempo. Desde el horizonte de sentido con la modernidad, la geografía es también un medio para la emancipación o el "antídoto", como nos diría Morín, desde el mismo Occidente. Unas geo-grafías para grafiar desde abajo, desde la tierra, además de ser más verbo y no sustantivo, como diría Porto-Gonçalves: Las geo-grafías políticas de la des/colonialidad del poder.
\end{abstract}

Palabras Clave: Geopolítica; Geografía política; Des/colonialidad; Geografías; Biologicismo.

\begin{abstract}
It is desired to open the debate within geography and its relationship with the social sciences on this dimensional milestone of the genesis of geography as a social science since Strabo, its institutionalization in academia, its genesis as political geography of Darwinian biologicist origin, its later mutation as geopolitics and its use as part of the expansionist policy of the imperial countries of the 19th century. Geography and his job as a geographer was transformed by geopolitics as a weapon of domination in the space and time of Europe and "Latin American"; Geopolitics and anarchist geography were victims of the consequences of hegemonies in the academic and military field, the first was accused of conspiring in favor of the Nazis in World War II and the anarchist theory was accused by Marxism of not being rigorous scientifically, both were disappeared or banned from the academy until recently. Geography from the horizon of meaning with modernity is also a means for emancipation or the "antidotes" as Morín would say to us from the same West, some geographies to graph from below and the earth as well as being more verb and not noun as Porto-Gonçalves would say: The political geo-graphs of the des / coloniality of power.
\end{abstract}

Keywords: Geopolitics; Political geography; Des / coloniality; Geographies; Biology.

\section{Citar como:}

Delgado, J. (2019). De la geopolítica de la dominación a las geo-grafías políticas de la des/colonialidad del poder. Espiral, revista de geografías y ciencias sociales, 1(1), 059 - 074. http://dx.doi.org/10.15381/espiral.v1i1.15846 


\begin{abstract}
"Pero la sociedad, en la humanidad, de ningún modo se ha creado sobre el amor ni tampoco sobre la simpatía. Se ha creado sobre la conciencia-aunque sea instintiva- de la solidaridad humana y de la dependencia recíproca de los hombres. Se ha creado sobre el reconocimiento inconsciente semiconsciente de la fuerza que la práctica común de dependencia estrecha de la felicidad de cada individuo de la felicidad de todos, y sobre los sentimientos de justicia o de equidad, que obligan al individuo a considerar los derechos de cada uno de los otros como iguales a sus propios derechos".
\end{abstract}

(Piotr Kropotkin: 1902; Introducción al apoyo mutuo).

\title{
1. Introducción
}

La Geografía Moderna le debe a tres factores clave su desarrollo: El contexto político económico, la enseñanza de la geografía y la geografía como ciencia. Además, para ser considerada una ciencia, deben sobresalir personalidades científicas como Humboldt ${ }^{1}$ y Ritter $^{2}$, pues ellos logran su inserción en las universidades europeas especialmente alemanas, tienen presencia, son consultados por las Sociedades Geográficas Imperiales, cuya creación data del siglo XIX ${ }^{3}$. En las Sociedades Geográficas Imperiales se inicia la recopilación y actualización de información y catastro de los recursos naturales realizados por viajeros, militares, científicos naturalistas de diferentes formaciones profesionales. Este trabajo fue financiado por grandes casas comerciales cuyos intereses económicos y políticos eran las inversiones y los negocios en diferentes continentes y países. Las maquinas a vapor luego de diésel acortaban los viajes marítimos y los ferrocarriles mejoraban las comunicaciones terrestres, mientras que el comercio de carga se profesionaliza y se vuelve masivo. El mundo se comienza a acelerar, las distancias se acortan y los viajes dejan de ser de exclusivos para las élites o aventureros.

La Geografía en las universidades europeas está en plena lucha entre sus métodos y teorías con otras disciplinas como la etnografía, biología y las ciencias políticas. Surgen más disciplinas y las fronteras del conocimiento se multiplican. Las Sociedades Geográficas son grandes empresas comerciales que ya no son necesariamente empresas familiares y, por tanto, se necesita un conocimiento más riguroso y científico de la geografía. Entonces empieza el envío de exploradores científicos, descubridores o viajeros, misiones comerciales y militares a las que les urge tener conocimientos más exhaustivos sobre esas regiones desconocidas y sobre las ex colonias de los imperios occidentales.

Cuando Charles Darwin (1809 - 1882) publica el "Origen de las Especies" en 1859, esta tiene importancia especial para la Geografía, singularmente para Frederich Ratzel quien es influenciado por esta obra y por el Naturalismo Científico. La influencia alcanzó a autores anteriores del siglo XVIII como Lamarck $(1744$ - 1829) quien propone en 1809, con su libro "Filosofía zoológica", que los organismos se adaptan al medio y pueden modificarse debido a que nada es inmutable.

La teoría evolucionista Darwiniana le puso un desafío a la Geografía moderna como ciencia, pues esta ya venía de la influencia de su creador griego Estrabón ${ }^{4}$ (64 a.C 24 d.C) en el siglo I. Estrabón estudiaba y observaba la relación del hombre con la 1 Fundador de la Sociedad Geográfica de Berlín en 1828.

2 Primer pprofesor de la cátedra de Geografía en la Universidad de Berlín en 1820.

3 La Sociedad Geográfica de París se crea en 1821, la Sociedad de Geografía de Berlín en 1828, la Real Sociedad de Geografía de Londres en 1830. Las sociedades geográficas no dejan de ser fuente de consulta sobre los amplios territorios de los continentes donde los poderes políticos tienen colonias o intereses comerciales. Dichas instituciones jugaron un papel importante en la definición de rutas marítimas o terrestres, la ubicación de algún recurso o bien natural usado como materias primas para las revoluciones industriales que acontecían en los países de Europa.

4 Estrabón era un geógrafo descriptivo que criticaba a los geógrafos matemáticos que era cartográficos o astronómicos, pero como sabemos eran Eratóstenes de Cirene o Hiparco de Nicea, ellos tenían méritos científicos como el primero que logro el medir el tamaño de la tierra y la inclinación de su eje gracias a su método trigonométrico. Eratóstenes de Cirene es considerado el padre de la Geografía Matemática o Geodesia.

060 | Espiral 1(1): 060 - 074 
tierra, los océanos, los fenómenos naturales y las sociedades de esos tiempos; estas relaciones las describió muy bien en su extensa obra "Geographica" (Geografía) de 17 volúmenes, fechada el 29 a.C, que contiene una visión enciclopédica de la civilización grecorromana del mundo occidental en aquella época.

Muchos siglos después, el geógrafo alemán Bernhardus Varenius (1622 - 1650) en el siglo XVII fue quien, con su monumental Geographia universalis (1650), nos dice que la geografía se divide en dos partes: Geografía universal o general y Geografía particular o especial; es decir, Varenius estudia las características y propiedades de la Tierra desde la Geografía matemática o astronómica y desde la Geografía física. En la primera y en la segunda estudia a los países, regiones o territorios parcelados, que agrupa en 3 clases: affectiones celestes, affectiones humanae y affectiones terrestres. La obra de Varenius influye hasta mediados del siglo XX y tiene repercusiones dentro del campo disciplinar de la geografía humana, astronómica o matemática y física.

La teoría darwinista conduce a la geografía a una tarea de reconocer las relaciones que tienen los seres vivos con el ambiente, no solo los identifica como formas vivas que transforman el ambiente. Para ello, la geografía es forzada a tener un método de explicación y análisis de los fenómenos multiescalares (locales, regionales y generales), tarea que ya Humboldt y Ritter nos habían recordado, pero es el alemán Ernest Haeckel (1834-1919) que en su libro "Morfología General de los Organismos", escrito en 1866, acuña y presenta el termino científico "Ecología" que dice es un nuevo campo de estudio de las relaciones del ambiente con los seres vivos.

Cuando la teoría darwiniana nos explica que la especie humana se impuso a los otros seres vivientes de su medio y/o entorno, dejó de ser homínida para ser el homo geographicus ${ }^{5}$, como lo conocemos hoy. Después se asentó y comenzó a ejercer una des/ territorialidad. En paralelo, extendió su cuerpo como un todo y parte para conectar la naturaleza humana y la no consciente, pero esto no tendría sentido sino fuera que busca el hombre al transformar sus territorios. Existe una postura, una tesis, una propuesta del estudio del espacio - tiempo y del ejercicio de la dominación de las relaciones hombre - naturaleza. Esta postura se enfrenta al darwinismo y al marxismo: La "Teoría del apoyo mutuo", publicado en 1902 en Inglaterra de Piotr Kropotkin (1842 - 1921) pero recibe el aporte y hasta trabajo previo de Élisée Reclus e Iliá Ilich Méchnikov (1845 - 1916) quienes nos dicen que la cooperación entre los seres vivos, respecto a su código social y biológico del más anciano o viejo, que transmite información al más nuevo o joven, es lo más importante de la evolución de las especies y no tanto la competencia y la lucha del más fuerte o ágil, frente al débil o lento: La cooperación es una alternativa a la competencia.

Esta propuesta alternativa al darwinismo social y su influencia en las jóvenes ciencias sociales, al recibir el aporte de Reclus y Mechnikov fue trabajada como "apoyo mutuo". Reclus prefiere continuar trabajando a base de la Mesología, que se inserta en lo que él llama la "geografía social". La "Mesología" es la ciencia que estudia las relaciones recíprocas entre los seres y su medio; en cambio, Mechnikov da una interpretación del darwinismo y dice que la fuerza central de la evolución es la cooperación y no la competición, y si existiera un nivel más alto de la evolución social, la cooperación no sería impuesta, más bien aceptada libremente en todo nivel de la vida social. No es otra cosa más que la anarquía. Proudhon no se había equivocado con su tesis de libertad y anarquía, en cambio Kropotkin ${ }^{6}$, observó en ese terreno (Siberia) las diversas formas solidarias y de cooperación que las plantas, animales, seres humanos, y entre seres de

5 "Para Sack, homo geographicus es la condición natural de los seres humanos que transformamos la tierra y la convertimos en nuestro hogar, y que a la vez somos afectados por ese mundo transformado. Homo geographicus es una condición ineludible, y acrecentar la conciencia de ello es necesario ahora que estamos convertidos en un leviatán geográfico capaz de destruir el complejo entramado de la vida en la tierra, constituido por la naturaleza, las relaciones sociales y los significados", (Ovidio Delgado Mahecha, 2003)

6 Kropotkin fue príncipe ruso y posteriormente oficial del ejército zarista, enviado a Siberia entre 1862 hasta 1867, donde realizo estudios y expediciones. 
especies diferentes, Kropotkin llega a la certeza que el anarquismo es el centro de la evolución y de las "ciencias positivas".

Fue Louis - Adolphe Bertillon (1821 - 1883) quien acuñó esta categoría "Mesología" frente a la otra categoría que tuvo mayor influencia y hegemonía en el mundo académico occidental, hasta nuestros días: la "Ecología", de Ernst Haeckel, No podemos dejar de mencionar que Bertillon también acuñó la categoría "Demografía".

Mención aparte es Pierre-Joseph Proudhon (1809 - 1865) quien es de cierta manera es él quien influencia a Bertillon con su término "mutualismo" y este posteriormente a Reclus y Kropotkin. No es otro que Reclus quien en su obra El hombre y la Tierra (1905), nos dice que hay que combinar el tiempo largo y el tiempo corto, a todas las diferentes escalas?.

$\mathrm{Al}$ existir un interés de las sociedades comerciales en conocer nuevos continentes, regiones, países y territorios, se necesita también conocer el país de origen y se necesita generar nacionalismos o Comunidades imaginadas (Benedict Anderson: 1993). Esa tarea recae en la geografía, con producciones editoriales como diccionarios geográficos, atlas geográficos y por supuesto su enseñanza en las escuelas medias y elementales. Pero son las élites nacionales imperiales europeas y las élites nacionales de las jóvenes Repúblicas en las "Américas" las que también empiezan a crear sus propias Sociedades Geográficas para sus intereses comerciales de ser proveedores de recursos naturales y de materias primas, dando inicio a lo que Pablo González (2003) denomina "Colonialismo Interno".

Tras la derrota de Francia en la guerra contra Prusia, se le encarga a Emile Levasseur (1828 - 1911) ${ }^{8}$ un estudio, el Informe Levasseur. En este documento, concluyó que los oficiales del ejército francés tenían una inferioridad del conocimiento de la cultura y la geografía de su país, y recomienda una reforma en la enseñanza primaria y secundaria francesa. Estas recomendaciones fueron replicadas en varios países europeos como Inglaterra, pero como sabemos ya en Alemania la geografía era importante en la creación imaginada de los Estados - nación y nacionalismos.

\section{Geopolítica de la Dominación}

Cuando la Geopolítica, "Geopolitik", nace y es acuñada en 1916 por el sueco Rudolf Kjellen (1846-1922), se desarrolla a partir de la concepción biologista del desarrollo de la sociedad, sobre la cual los diversos territorios tenían una notable influencia. Por eso, se entiende que la geopolítica tiene sus bases en la concepción del determinismo geográfico alemán de Frederick Ratzel, quien formula las "leyes del crecimiento del Estado"10. Esta obra tiene una influencia de la teoría evolucionista darwiniana y sostiene que el Estado, al ser un organismo vivo, está en una constante adaptación y selección natural. Ratzel analizó la evolución de los Estados desde la Grecia antigua hasta la Prusia de ese entonces, que es la Alemania de hoy. Estudia acerca de la sociedad, del Estado y de la naturaleza ocupada por estos; así, plantea a la sociedad y al Estado una política exterior expansionista, porque la geopolítica es el instrumento eficaz al servicio de los imperialismos (alemán, francés y británico) y a las oligarquías expansionistas e imperialistas de la Europa occidental de inicios del siglo XX, que para entonces habían perdido sus colonias en otros continentes.

\footnotetext{
7 "La historia de la humanidad en su conjunto y en sus partes no puede explicarse sino por la adición de medios con 'intereses compuestos' durante la sucesión de los siglos; pero para comprender bien la evolución que ha tenido lugar, hay que apreciar también en qué medida han evolucionado los propios medios, debido a la transformación general, modificando, en consecuencia, su acción". (É. Reclus, 1905:119).

8 Levasseur fue presidente honorario de la sociedad geográfica de Paris y miembro del Consejo de Instrucción Pública de Francia.

9 Kjellén, Rudolf. El Estado como forma de vida, (1916)

10 Ratzel, Frederick. Antropogeografia Vol. 11882 y Vol. 21891
}

062 | Espiral 1(1): 062 - 074 
Frederick Ratzel en 1896 publica su obra "Politische Geographie"11 (Geografía Política), donde nos da tres conceptos clave que son piezas angulares del pensamiento de Ratzel: La extensión (Raum), las fronteras (Grenzen) y la posición (Lage), que proporcionan los parámetros de lo que Ratzel llama la organización política del suelo. Es aquí donde Ratzel afirma que los Estados, al ser organismos vivos, nacen, crecen, se reproducen (expanden) y mueren. Los estudiosos de la teoría de la geopolítica nos precisan que es parte de la construcción del "Lebensraum", o espacio vital (1902), por lo que el nazismo se apropió de ello para justificar su expansionismo militar en Europa y así ampliar sus fronteras nacionales sobre las fronteras naturales de ese entonces.

La hegemonía dentro de la geografía, que ya se está estableciendo en la academia eurocéntrica, se manifiesta cercana al darwinismo ${ }^{12}$, que entonces es lo predominante dentro de las ciencias de fines del siglo XIX e inicios del XX. También fue predominante la teoría positivista de Comte, quien nos hablaba de las ciencias naturales de la sociedad, hoy ciencias sociales, y que para ello se dedicó más a estudiar la relación capital-trabajo antes que la relación capital/naturaleza. Así, no fue fácil diferenciarse de las "ciencias naturales", debido a que en ese entonces casi todos los académicos tenían un perfil biologista, tal como expresa Rudolf Kjellen al decir que la "geopolítica es la ciencia que concibe al Estado como un organismo geográfico o como un fenómeno en el espacio ${ }^{13}$ ". En este esfuerzo de conceptualización de la geopolítica, a partir de la articulación del determinismo geográfico con la concepción biologista de la sociedad, Kjellen ha llegado a la conclusión de que "La geopolítica es la teoría del Estado en cuanto a organismo geográfico o en cuanto a fenómeno en el espacio; es decir, en cuanto al Estado como país, territorio, suelo o, de una manera más característica, como imperio" (Marini, 1985: 41).

Para Kjellén, la Geopolitik estudia al Estado fundamentalmente como organismo geográfico vivo y solo secundariamente como soberanía; es decir, como poder político que subordina a la ley. Esta articulación del determinismo geográfico con el biologismo, define una forma específica de concepción del Estado y en ello radica el carácter biologista - geográfico de la geopolítica. Existían para Kjellén 4 ramas o campos adicionales de estudio como: "La Demopolitik dedicándose a estudiar a la población; La Sociopolitik que estudia la estructura de gobierno; Kratopolitik estudia la constitución y la organización gubernamental y Oekopolitik que examina los recursos económicos del Estado" (CAIRO, 2012: 338). "Es la influencia de los factores geográficos, en la más amplia acepción de la palabra, en el desarrollo político en la vida de los pueblos y Estados"14.

Con respecto al Estado, Kjellen señala que solo por la conquista de otros espacios o territorios que estén deshabitados o poco habitado, los denomina "espacio vacío", y si es lo contrario sería "espacio lleno"; por ende, la conquista de espacios llenos es más difícil que la de los espacios vacíos.

Según Kjellén (1916), solo vive y sobrevive el Estado gracias a su "espacio vital". Este es el espacio donde se desarrolla y que puede llegar a faltarle. Así, el Estado se expande en busca de más espacio vital, generalmente por la vía militar (aunque en la actualidad se pueden agregar otras variables, como económicas, culturales, políticas, etc).

11 Ratzel nos explica en esta obra que la "Posición" sería el "contacto constante al suelo", "que pertenece a una cierta porción de la superficie terrestre" (Politische Geografía, pag. 129). Así, vale más que un Estado tenga una posición central antes que una periférica, ya que un gran Estado frente a otro pequeño genera un proceso inevitable de anexión del pequeño Estado. La posición se fundamenta con la posición política (afiliación política de tal porción de tierra correspondiente a tal posición natural) y posición natural (ubicación geográfica de latitud y longitud). La Política Europea de Vecindad actual vendría a ser lo que se dice en la pag. 151 "vecindario político". La UE genera el dialogo en temas como la seguridad y el desarrollo económico con sus vecinos cercanos que tienen frontera marítima o terrestre.

12 Ratzel no solo recibió influencia de Darwin, sino también de Haeckel, Spencer y especialmente de Moritz Wagner. Este último fue clave para que su concepto de Lebensgebiet (territorio vital) que es la dependencia de un territorio, sea adaptado y revisitado en el famoso Lebensraum (espacio vital), luego controvertido y pervertido por los nazis.

13 Strausz - Hupé, Robert Geopolítica, en Rattenbach Augusto, 1975 Antología Geopolítica Ed Pleamar, Buenos Aires pág. 55págs. 61-62

14 Atencio, Jorge op. cit, pp. 24-25. Jorge Atencio también asegura que Kjellén definió la Geopolítica como “(...) la ciencia que concibe al Estado como un organismo geográfico o como un fenómeno en el espacio”, p. 23.

Espiral 1(1): $063-074 \mid 063$ 
Las guerras son un fenómeno normal y natural en la historia y en la existencia de los Estados. Así, al ser la guerra una necesidad de la existencia de los Estados, el ser humano ha perdido su libertad y es víctima del expansionismo de una entidad geográfica-biológica que sacrifica hombres hasta sus últimas posibilidades de paz y tranquilidad. Kjellén consideraba a la Geopolítica la "Ciencia del Estado" (Staatswissenschaft).

La autarquía, por lo tanto, no es más que la individualidad económica del Estado, del mismo modo que su territorio físico es su individualidad geográfica, y su nacionalidad su individualidad étnica. La política económica se convierte en un sinónimo de la geopolítica y también coincide con la etnopolítica, que exige una población homogénea. Las economías autárquicas difieren nacional y geográficamente. Así, de acuerdo con la ley de la vida totalmente organizada, la personalidad del Estado se refleja en sus diversos aspectos. ${ }^{15}$ (Kjellén, 2012: 2)

Al otro lado del Atlántico, la independencia de Estados Unidos (1783) permitió el desarrollo acelerado del capitalismo en base a las inmensas tierras y recursos naturales del oeste norteamericano. Ello fue posible con el exterminio de pueblos originarios y su reducción en pequeñas zonas o reservas. En cambio, en México, América Central y Sudamérica, recién se luchaba por la independencia, proceso que duró de 1809 a 1825 aproximadamente. Pero la respuesta de Europa fue pronta y se formó entre las monarquías de Austria, Prusia y Rusia, un bloque político- militar llamado la "Santa Alianza", a la que se le unieron todas las monarquías europeas.

La "Santa Alianza", tenía como objetivo la preservación de la monarquía y la religión católica en Europa, mediante la represión de los movimientos revolucionarios burgueses de las colonias americanas. Es así que enviaron a España, un ejército francés. Por otra parte, la "Santa Alianza" tenía también intenciones de restaurar el dominio colonial de los reinos europeos, idea que era compartida por Inglaterra. De esta forma, la "Santa Alianza" era un peligro no solo para las ex-colonias españolas, sino también para Estados Unidos. Ante esta situación, el presidente norteamericano James Monroe, el 2 de diciembre de 1823, manifestó ante el congreso de su país, la actitud que tomaría los Estados Unidos si se efectivizaban las ideas de la "Santa Alianza". Las partes más sustanciales de dicho mensaje expresan lo siguiente:

\begin{abstract}
“Consideraríamos un peligro para nuestra paz y seguridad cualquier tentativa de parte de ellas que tuviera por objeto extender su sistema a alguna porción de este hemisferio... cualquier intervención de una potencia europea con el objeto de oprimirlos o de dirigir de alguna manera sus destinos, no podrá ser vista por nosotros sino como la manifestación de una actitud hostil hacia los Estados Unidos... Es, por lo tanto, imposible que consideremos con indiferencia tal intervención, sea cual fuere la forma bajo la cual se presente"... "están implicados los derechos e intereses de los Estados Unidos, que los continentes Americanos, debido a la condición libre e independiente que han asumido y mantienen, no podrán ser considerados en adelante como objetos de futuras colonizaciones por parte de cualquier potencia europea". ${ }^{16}$
\end{abstract}

Este mensaje y la política exterior estadounidense contenida en él, fueron sistematizados en la frase siguiente: "América para los americanos". Es este mensaje que se conoce como la "Doctrina Monroe".

A finales del siglo XIX el Almirante Alfred T. Mahan, escribió su obra "The Influence of Sea Power upon History", 1660-1783" cuya traducción sería "La influencia del poder naval en la historia 1660-1783" (1890), donde Mahan sostiene la importancia que tienen el comercio marítimo y el poderío naval para el dominio político norteamericano a nivel mundial:

\footnotetext{
"Cuando Mahan habla de poderío naval no está hablando tan solo de la marina de guerra; para él existe una relación indisoluble entre una marina de guerra poderosa, un comercio marítimo importante y la posesión de colonias"17.
}

15 Kjellen, Rudolf, Autarquía en Rattenbach B., Augusto (compilador), Antología Geopolítica, Editorial Pleamar, Buenos Aires, 1975, pp. 55-62. http://investigacion.politicas.unam.mx/geopolitica/in305712/ene_mar2012.pdf

16 Sánchez, Luis Alberto Historia general de América, tomo II, pág. 755.

17 López, José I. (1993). Una visión del futuro: La Geopolítica de Alfred Mahan. Revista Universidad EAFIT, (91), 73-80

064 | Espiral 1(1): 064 - 074 
Para que las ideas de Mahan se materialicen los Estados Unidos deberían de expandir sus dominios marítimos y de ultramar los cuales realizaron en:

1867: Compra de Alaska a Rusia.

1897 - 1900: Anexión e incorporación de Hawái como territorio norteamericano, en 1958 se convirtió en el estado 50 de los Estados Unidos de América.

1898: Guerra con España, anexión de Cuba, Guam, Puerto Rico y Filipinas que se vuelven territorios ocupados, Estados libres asociados o independientes años después.

1899: Anexión de la isla Wake ubicada en el Micronesia del norte del Océano Pacifico.

1903: Separación de Panamá de Colombia, y en 1914 se apertura el Canal de Panamá para el comercio marítimo internacional administrado por Estados Unidos, hasta 1999 que lo devuelve a Panamá.

1905: Crea protectorados en Haití, República Dominicana, Nicaragua y Guatemala.

En ese contexto de expansión marítima de los Estados Unidos propuesto por Mahan fueron dejando su aislamiento, ya tienen todos los elementos del Poder naval, que es igual a marina de guerra, más comercio marítimo, más colonia y consideraba que el éxito de Inglaterra como potencia mundial naval residía en el hecho que contara con todos esos elementos.

Serían estos nuevos territorios a los cuales se refería como "isla" o "insularidad", no dentro del concepto geográfico sino geopolítico. Las amplias zonas marítimas que rodean las islas son una oportunidad para incrementar el poderío naval, el equilibrio entre la región costera y la región mediterránea. La población costera era relativamente elevada (en términos demográficos) respecto a la del interior, y el carácter socio - económico estuvo fuertemente influenciado por el mar, principalmente por el comercio. Por lo mismo, Mahan creía que una política naval acertada era la penetración y el dominio de los mares y océanos que anule la influencia de las escuadras extranjeras y, de esta forma, fortalecerían el poderío naval de Estados Unidos en los océanos y mares circundantes a su espacio terrestre, dándole a la vez el dominio mercantil y marítimo. En ese sentido, expresó que "el poder marítimo es la base vital del poderío de un Estado".

Los estudios de geopolítica se dan intensamente en Alemania dentro la Universidad de Múnich, pues en 1924 se funda la Revista "Zeitschrift Für Geopolitik "(Revista de Geopolítica) desde el Instituto de Geografía de Múnich, dirigida por Karl Haushofer (1869 - 1946). Militar y profesor de esa universidad, Haushofer sostiene que "el espacio rige la historia de la humanidad. No obstante eso, ¿Cuántas naciones se dan realmente cuenta de la importancia que tiene un planteamiento adecuado de materia de espacio? ${ }^{18}$. Asimismo, considera que "geopolítica es la ciencia que trata de la dependencia de los hechos políticos con relación al suelo. Se basa en los amplios fundamentos de la geografía, especialmente la Geografía Politica, y es la doctrina de la estructura espacial de los organismos politicos"19. En síntesis, la geopolítica tiene su objeto de estudio en la relación del suelo y la dependencia del Estado, de alguna forma es la influencia determinista que ve, pese que las ciencias sociales siempre la han criticado porque esa relación es casi nula entre el Estado y la sociedad, tal como lo dice Michel Foucault con sus estudios del poder.

Ante estas necesidades de los países imperialistas, de una doctrina que legitimara sus acciones, ya había aparecido el determinismo geográfico de Ratzel, mediante el cual, tanto los alemanes como los ingleses y posteriormente los norteamericanos, pretendieron justificar y hacer aparecer sus expansionismos como algo natural e inevitable. En ese sentido, con la aparición del imperialismo y la tendencia geográfica

18 Haustofer, Karl Poder y espacio en Rattenbach Augusto, 1975 Antología Geopolítica Ed Pleamar, Buenos Aires pág. 55 pág. 83 19 Weigert, Hans W. Geopolítica: generales y geógrafos, pág. 17.

Espiral 1(1): $065-074 \mid 065$ 
del desarrollo social, no es casualidad entonces que los países imperialistas de la Europa Occidental se dediquen a su expansión territorial y económica.

Delos teóricos alemanes, quien llega a algo más claro y aplicado es Halford J. Mackinder, al sustentar el 25 de enero de 1904 su discurso ante la Real Sociedad Geográfica de Londres, titulado "The Geographical Pivot of History", base de su teoría del corazón continental (terrestre) o "Heartland". Quizá se trate de la teoría más articulada a las concepciones del biologismo que no pasó por la censura de los vencedores de la II Guerra Mundial, que se convirtió en la geopolítica occidental y de sus ejércitos como doctrina, que es, a fin de cuentas, la que aprueba las prácticas agresivas de los países imperialistas en nombre del "Mundo libre" y la democracia.

\begin{abstract}
"Otro campo de discusión el cual le interesa directamente a Ratzel es el de la ciencia política. Temas como el del Estado, de las relaciones internacionales, de las fronteras, o de la guerra, entre otros, están al centro de sus reflexiones, Ratzel escribe inclusive un trabajo con el título, hasta entonces inédito, de Geografía política. Fue fundamentalmente a partir de sus argumentaciones que se desarrollaron las doctrinas geopolíticas de Mackinder, Kjellen y Haushofer. La influencia ratzeliana en ese campo extrapola la geopolítica aflorando en autores tan diferentes como Toynbee o Plekhanov. En lo esencial sus tesis estarán en las bases de algunas argumentaciones del pensamiento político conservador, vigentes hasta hoy". ${ }^{20}$
\end{abstract}

Las ideas de Mahan del poder marítimo, desde mi punto de vista son complementadas por el almirante Mackinder y las supera en la obra de 1904. Simplificando la lectura del planisferio, considera a Europa, Asia y África, como un bloque dentro de la vida política terrestre, llamado por él "La isla del mundo", y nos dice que el siglo XX podría ser el siglo donde el poder terrestre sea. Tradicionalmente, el poder se ejercía desde una base geográfica ubicada entre la Europa Oriental y el Asia Occidental, región generalmente conocida como Eurasia, a la que llamó "Heartland", "teoría del corazón continental" o "área pivote", quien domine o gobierne esa parte del mundo dominará el mundo. Según Mackinder, la posesión de esta región ha sido la causante de las luchas intestinas de Europa, a la vez que la impulsora indirecta de su desarrollo y por lo mismo, la base de toda la historia occidental, es decir la mundial.

Así, para Mackinder la historia y el desarrollo de la sociedad europea occidental y del mundo, solo sería una consecuencia de la influencia de la geografía política y geopolítica de la dominación, y es desde la política exterior o relaciones exteriores que se ha influenciado de ella. Además, la doctrina militar occidental jugó su papel, aunque se crea que Mackinder fue geoestratega, se dice que no llegó a serlo, sino que habría sido un economista político que habló en clave de geografía política (Taylor, 1993:51)

\title{
La Geografía Política de la postguerra, crisis epistémica
}

Después de la II Guerra Mundial y los sucesos posteriores en Europa, donde los académicos huyen de la Europa devastada por los bombardeos y los acuerdos de Yalta sobre la división de Europa, después de la caída del régimen nazi de Alemania y la toma de Berlín por parte del ejército rojo soviético y el ejército aliado. Pero siguen los acontecimientos mundiales: La revolución China (1949), la guerra de Corea (1955), la revolución cubana (1959), las independencias de las colonias en África, Asia y las Américas, finalmente la guerra de Vietnam (1960). Estos acontecimientos marcan la pauta de la llamada guerra fría o mundo bipolar (USA y la URRS).

El conocimiento no es ajeno a la realidad y se resignifica. Se habla sobre la crisis epistémica de las ciencias sociales, el giro cultural ha surgido, se aceptan los micro relatos, la literatura de no ficción, la modernidad crea la postmodernidad. Es la Escuela de Birmingham con los "Estudios Culturales" la que tiene una aceptación rápida en la academia anglosajona y una influencia en la geografía, notablemente con Richard 
Hoggart, Stuart Hall y Raymond Williams, siendo estos dos últimos los máximos referentes. Surge entonces una "nueva geografía cultural".

\begin{abstract}
"Esa "nueva geografía" está apoyada y proyectada hacia los "paisajes simbólicos" desde enfoques claramente interpretativos (Cosgrove 1984; Cosgrove y Daniels 1987), aduciendo metodologías analíticas ligadas al análisis textual, donde el espacio resulta ser un texto marcado histórica y culturalmente en el cual pueden observarse y "leerse" las marcas simbólicas características de una sociedad" (Zapata, 2011:168).
\end{abstract}

Al mismo tiempo que volvía el positivismo (neopositivismo), surgen la criticas y el rompimiento con el momento geográfico moderno-biologista de base darwiniana, los fundadores de la geografía política y geopolítica moderna son considerados colaboradores de los regímenes nazis, fascistas e imperialistas, pues sus textos académicos sufren una persecución y son olvidados por los académicos norteamericanos y europeos. Aunque tuvieron discípulos y divulgadores de sus planteamientos, como Ellen Churchill Semple (1863 - 1932), quien en sus obras reflejaba influencia de Ratzel y lo difundía a la academia anglosajona. Churchill centraba la Antropogeografia y el ambientalismo en el debate sobre el determinismo ambiental, siendo el espacio vital el centro de las actividades humanas.

\footnotetext{
"Una tierra es entendida por completo sólo cuando se estudia a la luz de su influencia sobre su gente, y un pueblo no puede ser entendido al margen del campo de sus actividades. Más aún, las actividades humanas son completamente inteligibles sólo en relación a las variadas condiciones geográficas que las han estimulado en diferentes partes del mundo" (1911: 51) ${ }^{21}$
}

Pese a la censura de la Geopolitik Alemana como instrumento nazi (Taylor y Flint, 2000: 57), y pese a la expulsión de la "International Geographical Union", un numero de geógrafos norteamericanos y europeos ${ }^{22}$ tomaron sus textos y los complementaron con la visión hegemónica de Mackinder, quizá el más conocido fue Isaiah Bowman (1878 - 1950) y se inicia la confusión entre los conceptos de geografía política y geopolítica. Bowman fue nombrado director de la "American Geographical Society", de 1915 a 1935, desde donde tuvo mucha influencia en la academia; además el asistió a la Conferencia de Paz en Paris de 1919, donde fue jefe de asesores de asuntos territoriales del presidente Woodrow Wilson y complementaba su influencia política en el establishment norteamericano., Luego publicó, en 1921, "The New World Problems in Political Geography"; se especializo en fronteras y estudió la disputa entre Perú y Ecuador de 1942. Su posición política conservadora lo llevó a mantener "la Doctrina Monroe, no sólo en términos económicos sino en términos militares; pues no veía ninguna contradicción entre la seguridad estadounidense y la seguridad del mundo" (Smith, 1994: 299).

La Escuela de Frankfurt será un elemento catalizador, casi un giro copernicano por unas ciencias sociales crítica. Será la Teoría Critica, presentada por Horkheimer en su artículo "Traditionelle und kritische theorie", publicado en 1937, donde por primera vez se involucró a la teoría y a la acción. Asimismo, decía que el científico social es parte del objeto que investiga, se aceptaba la imaginación estética y la fantasía para entender la realidad social. Pero no fue hasta 1961 que Theodor Adorno, con su ponencia "Sociología e investigación empírica", quien critica al positivismo y al empirismo como método científico válido dentro de las ciencias sociales, pues las alejaba de un compromiso social del académico debido a su exigencia de neutralidad por parte del científico social de ese entonces y podríamos decir hasta la fecha.

En medio de ese debate, que no es ajeno a la geografía, se creó una "nueva geografía" (o "New Geography") especialmente en USA e Inglaterra, que trae consigo a la Geografía Teorética-cuantitativa como también se le conocía. Se pone énfasis en los modelos y leyes, para algunos críticos era la vuelta al "neopositivismo filosófico".

21 Cairo, Heriberto (2011) “La Geopolítica como «ciencia del Estado»: el mundo del general Haushofer". Geopolítica(s). Revista de estudios sobre espacio y poder, vol. 3, núm. 2, 337-345

22 Ver Richard Hartshorne (1933), Andreas Dorpalen (1942), Jacques Ancel (1936), Derwent Stainthorpe Whittlesey (1939), Jean Gottmann (1952), Umberto Toschi (1959) Robert Strausz-Hupé (1942).

Espiral 1(1): $067-074 \mid 067$ 
Dentro de ese nuevo reposicionamiento de la geografía de postguerra hay tres críticas o miradas que son las más resaltantes la geografía radical, la geografía humanista y la geografía del comportamiento. Nos enfocaremos en la primera, pero no podemos dejar de mencionar que la geografía de la percepción y del comportamiento abrió la brecha frente al debate con la geografía neopositivista o nueva geografía. Por supuesto, con la influencia de la fenomenología y el existencialismo que desde Europa migró al mundo anglosajón e influyó muchísimo en cuestionar y poner en el centro de la discusión al Sujeto y la subjetividad. De este modo, se reconoce la experiencia e imaginario, pero sobretodo el investigador social se vuelve observador - participante.

\begin{abstract}
"Geosofia... es el estudio del conocimiento geográfico desde cualquier o todos los puntos de vista. Es para la geografía lo que la historiografía es para la historia; trata de la naturaleza y la expresión del conocimiento geográfico en el pasado y presente con el que Whittlesey llamó "sentido humano de espacio terrestre.". Esto se extiende entonces mucho más allá del núcleo del conocimiento científico geográfico o del conocimiento geográfico sistematizado de otras formas por los geógrafos. Teniendo en cuenta todo el dominio periférico, cubre las ideas geográficas, verdaderas y falsas que no son solo de los geógrafos, sino de todas maneras (formas) de personas, hacendados, pescadores, empresarios, poetas, novelista, pintores, beduinos o Hottentot y por esta razón necesariamente tiene mucho que ver con concepciones subjetivas". (John K. Wright, 1947)
\end{abstract}

Por ser de nuestro interés principal pues la geografía radical surge propiamente en los años sesenta en medio del proceso de los problemas sociales dentro de USA, por eso se organizan al mismo tiempo en Chicago y otras ciudades las "expediciones geográficas" y los eventos de París como el "Mayo francés del 68". Después, en los años setenta comienzan los artículos sobre geografía que trataban temas más "relevantes socialmente" (Vg. Morrill 1969-70; Albaum 1973), además se crean dos organizaciones radicales, la "Union of socialist geographers - USG" fundada en 1974, y la "Socially and Ecologically Responsible geographers - SERGE". Finalmente empezaron a aparecer en algunas de las publicaciones de la corriente principal de la disciplina y desde 1969 con la fundación de Antipode: "A Radical Journal of Geography" (editada por Richard Peet en Clark University) es donde tienen la visibilidad dentro de la academia.

La Geografía Política no es ajena todos los acontecimientos mundiales de la "Realpolik", donde las luchas por los derechos civiles como el voto femenino y la no segregación racial, la crítica a posibles guerras mundiales y el aceleramiento de un nuevo proceso de industrialización en el mundo occidental surgen en paralelo a una "conciencia ambiental" en la ciudadanía. Dentro de la academia geográfica también surge, en 1975 la "New Political Geography" y más adelante tendría una visibilidad con el "Journal of Political Geography".

Surge entonces la ruptura con la geopolítica clásica, pero rescatando aquella de base ratzeliana, como a Kjellen y Mackinder, buscando un énfasis más riguroso en términos teóricos y metodológicos. La geografía política es la ciencia que no solo estudia el Estado-nación sino también el poder en sus diferentes manifestaciones multiescalares y su honda preocupación con la Guerra Fría, con la ideología y los sistemas socioeconómicos. Finalmente, se da el debilitamiento o extinción de la escuela alemana y el fortalecimiento de las escuelas francesa y norteamericana, que tiene entre sus autores más sobresalientes y renombrados a Hartshorne (1950), Gottmann (1952), Pounds (1957), Alexander (1957), Cohen (1963) y George (1965).

La "Nueva Geografía Política" o la geografía del poder, ¿es la Geopolítica, crítica? o ¿la geografía de los conflictos? o ¿el estudio geográfico de los fenómenos de dominación? Esta "nueva geografía política" comenzó desde finales de 1960 y especialmente en la década de 1970, estuvo vinculada a la aparición de nuevos actores: el feminismo, las luchas contra la guerra de Vietnam y los derechos civiles, el mayo de 1968, la contracultura, etc. Por lo tanto, hay una preocupación por los nuevos agentes, actores y por las nuevas formas de lucha, mas mediáticas que callejeras, mas académicas que políticas, pero que una no se desprende de la otra, entre ellas las relaciones 
de género hegemónico patriarcal, la libertad sexual y de los cuerpos, los conflictos culturales y etno-territoriales, las nuevas des/territorialidades, la marginación y exclusión, la subalternidad, los saberes sometidos, etc.; Potencia (o poderes) de los nuevos estados independientes que luchan contra el colonialismo eurocéntrico.

Ahora, los estudios de geografía política, de las relaciones de poder (o de las relaciones de dominación), "el estudio de las diferencias y semejanzas de carácter político de un área como relacionada con el complejo total de diferencias y semejanzas en esa zona" Hartshorne (1954).

La geografía política es el enlace con las ciencias sociales por su interés en la acción espacial entre los fenómenos geográficos y políticos, porque tienen que demostrar las causas y efectos espaciales de los procesos políticos, porque si no se encontrara alguno de ellos no existiría la geografía política. Anteriormente, la influencia de la historia en la geografía política se da por ese fuerte vínculo clásico entre ellas, pero ahora hay más amplitud dentro de las ciencias sociales (sociología, ciencias políticas, relaciones internacionales, etnología, economía, etc.). Cohen y Rosenthal formulan un modelo geográfico de análisis de los sistemas políticos, para lo cual partieron de la premisa "la geografía política se relaciona con los atributos espaciales del proceso político", analizando el proceso y sus atributos espaciales, dentro de un método de sistemas amplio, capaz de cubrir la relación entre el hombre político y el medio ambiente. No puedo olvidar de mencionar desde la perspectiva crítica, la asignación de funciones o usos que son de tipo social, económico, cultural y político, o mejor dicho, un uso- interrelaciones e interacciones -entre los hombres y la naturaleza de la superficie terrestre son las que teóricamente delimitan y explican la organización espacial, que algunos geógrafos denominan también como "espacio-producto" (Koninck, 1984).

Una nueva evaluación y lectura de la Geopolítica se inició con Yves Lacoste y su revista "Hérodote" (1976). Una geopolítica ya no al servicio de los estados totalitarios, sino una geopolítica crítica, con esta nueva geopolítica crítica, los autores eran tan críticos y radicales como Marx y Gramsci, además el marxismo tenía sus variables académicas, entre ellas la escuela crítica de Frankfurt (Marcuse, Adorno y Horkheimer). Asimismo, los posestructuralistas como Foucault, por su trabajo sobre el poder, que nos recuerda que este no necesariamente está en el Estado, y que las relaciones del Estado con el conocimiento y el discurso producen la "Biopolitica".

\section{La Geografía política y Geopolítica Latinoamericana}

La geografía como disciplina moderna en Latinoamérica tiene su origen en las independencias, cuando las élites criollas necesitaron realizar un catastro de los recursos naturales e iniciar el colonialismo interno en las jóvenes repúblicas. Son los militares quienes se declaran depositarios de la cartografía oficial, también las sociedades geográficas de los países latinoamericanos, que no son más que corresponsales de las sociedades geográficas de los imperios europeos de tradición decimonónica. Pero en Latinoamérica, así como en Europa, también se comienza a enseñar la geografía en las escuelas y en las universidades; es decir, empieza su institucionalidad académica. Asimismo, se crea el imaginario de Estado nación a través de los Atlas, se conoce la geografía física y la cultura de cada país.

En el siglo XXI después de muchas guerras internas y conflictos entre países limítrofes en Latinoamérica y el Caribe, Estados Unidos se impone como una potencia militar y política en nuestro continente al vencer a España a fines del siglo XIX. Inicia su hegemonía siendo garante de acuerdos de paz, de tratados y hasta de gobiernos de turno, especialmente en Centroamérica. No contentos con ello, imponen en el campo militar la geopolítica como ciencia militar, forma escuelas militares donde los oficiales latinoamericanos son educados bajo la doctrina militar de Mackinder y Mahan. Pero no podemos dejar de mencionar que los ejércitos latinoamericanos ya

Espiral 1(1): 069 - 074 | 069 
tenían influencia francesa y prusiana, especialmente en los ejércitos sudamericanos. Esta geopolítica clásica entra en crisis en la postguerra y no es hasta fines de los años sesenta que se vuelve popular nuevamente en el ámbito académico y militar de América Latina. Será justamente Henry Kissinger quien, entre su puesto como asesor de Seguridad Nacional en 1968 y como Secretario de Estado después, entre 1973 hasta 1977 lo pronuncia nuevamente en discursos oficiales dentro del establishment y academia de USA que la vuelva nuevamente popular inicialmente en el periodismo.

Desde fines de los años 70’s los geógrafos latinoamericanos están tratando de lograr salir de esa escuela descriptiva, decimonónica, positivista y que fue herramienta de la dominación de nuestros pueblos. Sin embargo, muchos países todavía se encuentran en ello, especialmente ahí donde los militares tienen el control cartográfico oficial y donde la geográfica académica aplicada es la oficial, su apéndice. En otros pocos países, sin embargo, están logrando resignificar y desarrollar saberes emancipatorios desde la geografía, dentro del quehacer geográfico académico y profesional.

Pero la realpolitik Latinoamericana tiene gobiernos en diversos momentos que buscan un desarrollo y cambio social con orientación nacionalista, y realizan cambios en la estructura política y económica de países muy diversos de América Latina. Obviamente las élites nacionales y las empresas transnacionales ven afectados sus intereses y se producen golpes de Estado de parte de militares educados en doctrinas hegemónicas de geografía política y geopolítica. Un ejemplo de ello es la célebre "Escuela de las Américas" del ejército estadounidense, con base en el canal de Panamá y administrado por ese país.

En nuestros países latinoamericanos existen muchas zonas o "territorios de sacrificios" donde se ejerce una relación asimétrica entre el poder y el espacio, sea urbano o rural. En esos espacios se genera una lucha por el uso del suelo, que termina siendo una lucha de clases, en el caso de Alain Musset (2009) en la búsqueda de la vulnerabilidad social y la justicia espacial, como se realizó en su momento en la revolución francesa ante el antiguo régimen, en la actualidad se ha utilizado mucho el concepto de justicia en diversos espacios pero generalmente se usa en la ciudad ante proyectos que buscan una integración, equidad y contrarrestar la segregación socio espacial en las urbes.

No podemos de dejar de citar a Walter Benjamín (1892 - 1940) quien en su obra "Tesis sobre la historia" (1940) que traducida por Bolívar Echevarría ( 2005), donde nos señala que la historia lo escriben los vencedores, que los cronistas realiza una relación entre pequeños y grandes, responde que nada debe ser dado por perdido en la historia, aparte que articular el pasado no significa sin el presente pues es ella la que desaparece que se no se encuentre dentro de ella, pues para Walter Benjamín la clase dominante solo ve los grandes momentos de la historia y de los vencedores, una crítica directa al Historicismo pero para el que se pregunta dónde están los vencidos "cada testimonio de cultura es al mismo tiempo un testimonio de barbarie". (Tesis VII), en síntesis, nos dice que no hay civilización sin barbarie, que son uno solo, que, tras una guerra, una conquista, es el inicio y hegemonía de una civilización, lo fue la romana, la hispana, la francesa, inglesa y norteamericana.

Benjamín da una crítica directa a nombre de los vencidos pues falta su versión, su mirada y eso es un nuevo método, enfoque y tesis para escribir la historia "desde abajo" que se podría aplicar a muchas disciplinas como la geografía y su historia de las ideas. No podemos dejar de mencionar que Morín (2006) menciona que la Barbarie occidental tiene sus antídotos y a través de la historia de occidente lo ha aplicado ${ }^{23}$.

\footnotetext{
23 "Si Europa occidental ha sido el hogar de la dominación bárbara sobre el mundo, también ha sido la cuna de las ideas Emancipatorias, como las de los derechos del hombre y las de ciudadanía, gracias al desarrollo del humanismo. Las ideas emancipatorias han sido retomadas por los representantes de los pueblos colonizados y sometidos a servidumbre: es a partir de los derechos de los pueblos, derechos del hombre y derechos de las naciones que los procesos de emancipación han tenido lugar" (Edgar Morín 2006:78).
}

070 | Espiral 1(1): 070 - 074 
Latinoamérica ${ }^{24}$, nuestro sujeto y objeto si tomamos a Benjamín, pues tiene una dialéctica de la moral, es decir al "cepillar la historia a contrapelo" y su mejor ejemplo de sus "Tesis sobre la historia", es la reseña que realizo en 1929 del libro "Bartolomé de Las Casas. "Père des Indiens", Paris, Plon ,1928", obra de Marcel Brion, cuya discusión dentro la iglesia católica hispana, que este había escrito sobre el cura español Bartolomé de las Casas quien defendía la causa indígena frente al oprobio y abuso de los conquistadores europeos en el "Nuevo Mundo"25.

José Carlos Mariátegui (1894 - 1930) en los Siete ensayos de interpretación de la realidad peruana (2007) nos refiere que el Tahuantinsuyo precolombino era una organización político administrativa casi colectivista - comunista con cierto éxito de ser una civilización que se llegó a un cenit de su expansión y desarrollo de su "tecne" y luego entro al "colapso" con la llegada del hombre europeo que inicio una deconstrucción de la civilización andino - amazónica, para decirlo de otra manera se inició la "Colonialidad del Poder".

Michael Löwy (2007) nos dice que los debates académicos por las celebraciones del Quinto Centenario de 1492 es un claro ejemplo de lo que Walter Benjamin nos quiere dar a conocer en sus "Tesis sobre la historia" pues los países y sus elites en complicidad con el sector conservador de la iglesia latinoamericana deseaba celebrar la llegada de Cristóbal Colon a nuestro continente, Walter Benjamin escribió sobre el "cortejo triunfal" de los amos y vencedores de la historia (Tesis VII "Sobre el concepto de la historia").

La historia de los vencidos la escribían los sectores de la iglesia cercana a la Teología de Liberación con Gustavo Gutiérrez, quien presenta su posición de rechazo a celebrar la llegada de los europeos a América, por supuesto es una nueva versión de la "dialéctica histórica" en el interior del catolicismo de la que hablaba Benjamín en su reseña del libro de Marcel Brion en 1929.

\section{Recomendaciones Finales}

La Geografía nos ajena a lo que se nos señala sobre que la historia la escriben los vencedores pues líneas arriba pudimos conocer como la geografía y geopolítica alemana fue acusada, proscrita, invisibilizada y censurada por ser el sustento académico de los nazis, que no deja de ser cierto en parte, pues la categoría Lebensraum (espacio vital) aparece en el libro de Hitler Mein Kampf, sino también porque son los vencidos de la II guerra mundial. El aporte de la geografía y geopolítica alemana es hoy fundamental pues nos trae el estudio del estado como organismo, su gen biologicista lo hace que una no puede estar lejos de la otra, las dos deterministas, la primera la base teórica y la segunda el arte por eso Haushofer, decía que la geopolítica era dinámica y la geografía política estática.

Mención aparte es la geografía de origen anarquista, pues se confunde el anarquismo académico como filosofía social de Kropotkin con su militancia en el anarquismo político a pesar que originariamente tienen sus pensamientos muy cercanos con el socialismo, pues los unía la eliminación de la propiedad privada, prácticamente en Latinoamérica se desconoce en demasía sus obras dentro de la geografía.Eso nos hace recordar nuestra participación en eventos académicos de la Union Geográfica Internacional en 2011 en Santiago de Chile en donde en la conferencia de la comisión

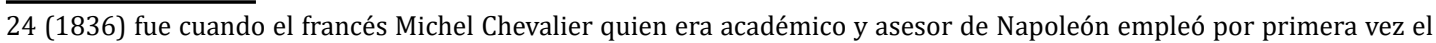
término América Latina en la Introducción de" Lettres sur l' Amérique du Nord", pues anteriormente a esta obra se usaba la "América Hispánica" y se deseaba combatir la doctrina Monroe de la "Panamérica" de influencia norteamericana.

25 "La Conquista, este primer capítulo de la historia colonial europea, escribe Benjamín, "transformó el mundo recientemente conquistado en una cámara de torturas". Las acciones de la "soldadesca hispánica" crearon una nueva configuración del espíritu (Geistesverfassung) "que no puede representarse sin horror (Grauen)". Como toda colonización, la del nuevo continente tenía sus razones económicas -los inmensos tesoros de oro y plata de las Américas- pero los teólogos oficiales intentaron justificarla con argumentos jurídico-religiosos: "América es un bien sin propietarios; la sumisión es una condición de la misión; intervenir contra los sacrificios humanos de los mexicanos es un deber cristiano” (Michael Löwy: 2007).

Espiral 1(1): 071 - 074 | 071 
de geografía histórica se mencionó estudios para visibilizar y rescatar de la censura política de la dictadura franquista y el olvido académico de geógrafos anarquistas españoles.

La geografía de los pueblos originarios del Abya Yala, de los Mexicas, Mayas e Incas entre otros pueblos más pequeños, se perdieron en el tiempo cuando se encontraron con la cultura europea, no es hasta que luego de las independencias y con la modernidad prometida se ha intentado rescatar los saberes sometidos a ese oscurantismo y colonialidad del poder que se le llamo extirpación de idolatrías que no fue más que una extensión en cuerpo y alma del eurocentrismo de tradición judío cristiana. En el caso del mundo andino - amazónico, existió sistemas de información geográfica tanto instrumental como los quipus y de tradición oral como los tocapus, una territorialidad material hegemónica desde Cusco como centro hacia el mundo andino - amazónico con el Qhapaq Ñan como instrumento, luego una reciprocidad y trabajo comunitario con un habitus originario desde el Ayllu, la producción del espacio entre su proceso y su producto existía, es más había un espacio físico, mental y social como nos dice Lefebvre: La trialectica de espacio, en nuestro caso andino amazónico.

El desafío para una geografía de la Des/colonialidad del Poder es reencontrar/ reencontrarse (con) la felicidad, el buen vivir o Sumak Kawsay (en quechua) como una construcción social que es la felicidad más como sueño que como ilusión, pues esta última ha sido construida desde el patrón moderno colonial con el discurso de los vencedores desde los poderes facticos (prensa, iglesia, raza, etc). La territorialidad, multiterritorialidad y des/territorialidad son multiescalares en esa dicotomía sociedad /naturaleza y objetiva o subjetiva, para eso siempre los geógrafos nos preguntamos ¿Para lo que sirve la geografía?, para este autor, pues sirve para comprender esos momentos de la felicidad del ser humano mientras piensa, ocupa y produce su/el espacio.

\section{Bibliografía}

Anderson, Benedict, (1993). Comunidades imaginadas: reflexiones sobre el origen y la difusión del nacionalismo. Buenos Aires: Fondo de Cultura Económica, 315 p.; 17 cm. Edición; 1a. ed.

Benjamin, Walter, Tesis sobre la historia y otros fragmentos, trad. Bolívar Echeverría, ed. Contra historias, 2005. (Traducido del alemán). Reeditado por editorial Itaca, 2008.

Bolívar Echeverría, Definición de la cultura. Curso de filosofía y economía, 1981-1982, editorial Itaca/UNAM FFyL, México 2001.

Bowman, I. (1942). “Geography versus Geopolitics”. Geographical Review, 32, 646-658.

Cairo, Heriberto (2010). “Comentario: «El pivote geográfico de la historia», el surgimiento de la geopolítica clásica y la persistencia de una interpretación telúrica de la política global". Geopolítica(s). Revista de estudios sobre espacio y poder, 1 (2), 321-331.

Cairo, Heriberto (2011). "La Geopolítica como «ciencia del Estado»: el mundo del general Haushofer". Geopolítica(s). Revista de estudios sobre espacio y poder, vol. 3, núm. 2, 337-345.

Dorpalen, Andreas. (1942). The world of general Haushofer. New York: Farrar and Rinehart, 234 pp.

Federico Ferretti, Philippe Pelletier (2013). En los orígenes de la geografía crítica. Espacialidades y relaciones de dominio en la obra de los geógrafos anarquistas Reclus, Kropotkin y Mechnikov. Germinal Revista de Estudios Libertarios, pp.57-72. < https://hal.archivesouvertes.fr/hal-00954956 >

Haushofer, Karl (2012).“Los fundamentos geográficos de la política exterior”. Geopolítica(s). Revista de estudios sobre espacio y poder, vol. 3, núm. 2, 329-336.

072 | Espiral 1(1): 072 - 074 
Lacoste, Yves (1977). La geografía: un arma para la guerra. Traducido por Joaquim Jordá, Barcelona: Anagrama 198 pp.

Löwy, Michael (2007). Avertissement d'incendie. Walter Benjamin. Une lecture des Thèses «Sur le concept d'histoire», Paris, PUF, 2004. Traducción de Faustino Eguberri <http:// www.eldiariointernacional.com/spip.php?article1120 >

Mackinder, Halford J. (2011) “El pivote geográfico de la historia”. Geopolítica(s).

Revista de estudios sobre espacio y poder, 1 (2), 301-319.

Mariátegui, José Carlos (2007). 7 ensayos de interpretación de la realidad peruana. Caracas: Fundación Biblioteca Ayacucho

Morín, Edgar (2006). Breve historia de la barbarie en Occidente. Editora Paidós.

RATZEL, F. (1988) Géographie Politique. Paris, Éditions Régionales Européennes.

Ratzel, Friedrich (1896) "Die Gesetze des räumlichen Wachstums der Staaten". Petermanns Geographische Mitteilungen, 42, 97-107 [trad. al castellano por M. Díaz: "Las leyes del crecimiento espacial de los Estados. Una contribución a la Geografía científico-política". Geopolítica(s). Revista de estudios sobre espacio y poder, 2 (1), 135-156].

Taylor, Peter J. (1993). Geografía política - Economía-mundo, Estado-nación y localidad. Trama Editorial. Primera, edición en español. Madrid, España, 339 pp.

Wright, John K. (1947) Terrae Incognitae: The Place of the Imagination in Geography, Annals of the Association of American Geographers, 37:1, 1-15. 
074 | Espiral 1(1): 074 - 074 